\title{
Post-earthquake spatio-temporal landslide analysis of Huisun Experimental Forest Station
}

\author{
Ming-Der Yang ${ }^{1,2,3}$ and Hui-Ping Tsai ${ }^{1,2,3, *}$ \\ ${ }^{1}$ Department of Civil Engineering, National Chung Hsing University, Taichung, Taiwan \\ ${ }^{2}$ Innovation and Development Center of Sustainable Agriculture, National Chung Hsing University, Taichung, Taiwan \\ ${ }^{3}$ Pervasive AI Research (PAIR) Labs, Hsinchu, Taiwan
}

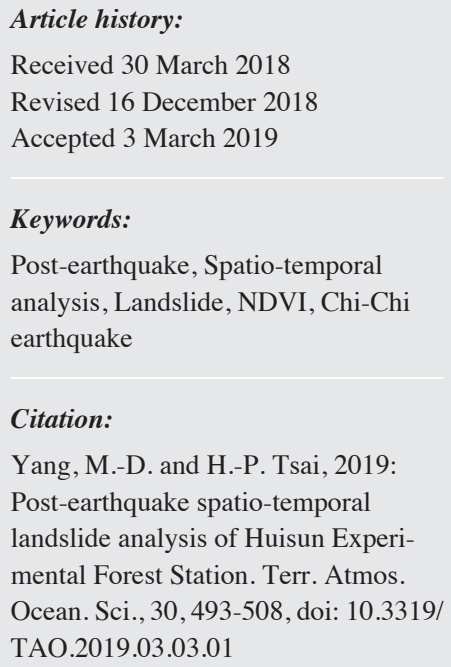

\begin{abstract}
The present study utilized satellite imagery and the Normalized Difference Vegetation Index (NDVI) to investigate the post-earthquake spatio-temporal changes of landslide for Huisun Experimental Forest Station (HEFS). Total 26 SPOT satellite images taken between January 1999 (before the Chi-Chi earthquake) and July 2016 shows that the total landslide area was fluctuated after the earthquake and then became stable after 2008. Overall, the long-term landslide trends of HEFS is approaching a stable stage in terms of the slightly increasing mean NDVI value with decreasing NDVI variance from 1999 to 2016 based on the linear regression and Mean-Variance analyses. Two large landslide areas in Xinsheng Village and along Meitangan River were identified as statistically significant hot spots. More than $50 \%$ of landslides in HEFS were observed in areas with S-facing and SE-facing slopes with the majority of landslides occurred at $500-1500 \mathrm{~m}$ elevation. The slope characteristic of landslides changed to a concentration in 30 - 40 degree after the Chi-Chi earthquake and changed again to a concentration in 20 - 30 degree after 2008. Based on the results of the frequency of landslide occurrence, the total landslide area was the largest in the $0-9$ times category. In the $10-16$ and $17-26$ times categories, high percentages of landslides were found in SE-facing and S-facing slopes. An inverse relationship was found between the landslide areas and the distance to river channel in the 0 - 9 and 10 - 16 times categories. The results of spatio-temporal landslide analysis can be references for management and conservation strategies in HEFS.
\end{abstract}

\section{INTRODUCTION}

In recent years, global climate patterns have changed at an unprecedented speed and extreme events occurred more frequently with a wide range of impacts. For instance, the phenomenon of low sea water temperature in 2008 associated with the El Niño Southern Oscillation (ENSO) and extreme cold front occurred in 2016 affected many agricultural and fishery industries in Taiwan (Chang et al. 2013; Wang et al. 2016). Additionally, Taiwan has a steep topography and is located at a compressive tectonic boundary between the Eurasian Plate and the Philippine Sea Plate, which results in frequent and complex seismic activities. As Taiwan locates in the north-western Pacific Ocean, the main warm pool for tropical cyclones formation, 3 - 4 typhoons make

\footnotetext{
* Corresponding author

E-mail: huiping.tsai@nchu.edu.tw
}

landfall in Taiwan every year. The extreme precipitation associated with typhoons often caused serious landslides damages in Taiwan (Lin et al. 2011a; Lin 2015; Lee 2017).

In 1999, the large-scaled Chi-Chi earthquake $\left(\mathrm{M}_{\mathrm{L}}=7.3\right.$ and $\mathrm{M}_{\mathrm{w}}=7.6$ ) occurred in Central Taiwan. Many mountainous areas were seriously damaged, vegetation was lost, and the surface strata were extensively disturbed. After the surface strata have been highly disturbed, typhoons and heavy rainfall events have triggered more landslides because of higher water infiltration in loose sediment (Chang and Slaymaker 2002; Lin et al. 2011b; Yang et al. 2011). Consequently, as frequent earthquakes, steep terrain, and typhoon incursions often pose great threats to the lives and property of Taiwan residents, a better understanding of long-term landslides spatial and temporal patterns in Central Taiwan is urgently needed. 
Taiwan has a wide mountainous area and a rugged terrain, which results in high inaccessibility for most mountainous regions, and it is more difficult for local investigations on landslides. Compared with traditional local investigations on landslides, remotely sensed data provides many advantages including higher spatial coverage and longer temporal coverage (Barrett 2013). Therefore, utilizing remotely sensed data to investigate landslides has become an efficient way to better interpret landslide patterns (Bozzano et al. 2017; Du et al. 2017; Qi et al. 2017). With the continuous development and progress of remote sensing technology, many new technology developments have contributed to the study of landslides. For instance, InSAR technology for surface deformation (Hetland et al. 2012; Chaussard et al. 2014; Lu and Dzurisin 2014), Light Detection and Ranging (LiDAR) and airborne Laser Scanning (ALS) (Pope and Treitz 2013; Johnson and Ouimet 2014; Plowright et al. 2016), Geographic Information System (GIS) combined with multi-scaled satellite imageries (Czerepowicz et al. 2012; Alexakis et al. 2013; Vibrans et al. 2013; Bhandari et al. 2014), and aerial photography using unmanned aerial vehicles (Turner et al. 2012; Mancini et al. 2013; Peña et al. 2013; Yang et al. 2017b) all have brought increasing attentions in landslide studies.

Using multi-date satellite image remote sensed data to analyse terrain vegetation has been recognized as an efficient way to distinguish vegetation recovery dynamics and trends on large-scaled landslides (Yang et al. 2013). The normalized difference vegetation index (NDVI) has been widely used to analyse seasonal trends of vegetation (Brandt et al. 2016; Maeda et al. 2016; Tsai et al. 2016), climate change trends (Pravalie et al. 2014; Li et al. 2015; Tsai and Yang 2016), vegetation health status (Yang et al. 2004, 2007; Yang 2007; Dutta et al. 2015; Gopinath 2015) and land use change (Adesuyi and Múnch 2015; Guan et al. 2017). Many scholars in Taiwan have applied NDVI derived from multi-date satellite images for landslide studies (Lin et al. 2004, 2006; Tsai et al. 2010; Yang et al. 2017a), which addresses vegetation recovery status after the ChiChi earthquake in Central Taiwan. Huisun Experimental Forest Station (HEFS), an important ecological conservation area in Central Taiwan (Hsieh et al. 2016), has been influenced by the Chi-Chi earthquake in 1999. Empowered by remotely sensed data availability, the present study aims to understand the long-term landslides spatial and temporal patterns in Central Taiwan by utilizing multi-date satellite images from 1999 to 2016 to evaluate the overall landslide changes in HEFS after the Chi-Chi earthquake. The results of the present study are expected to be important in terms of contributions to a better and deeper understanding of landslide occurrence in Central Taiwan. Additionally, the characteristics of landslides are analyzed both spatially and temporally. Moreover, this study also carries out spatial hotspot analysis of landslides and conducts in-depth discussions on long-term vegetation and landslide trends. As the landslides in HSFS been characterized, detailed quantitative properties can serve as a fundamental tool both for improving the efficiency of management and conservation and also for enhancing relevant modeling geo-processes related to landslide dynamics in the future.

\section{MATERIALS AND METHODS}

\subsection{Study Site}

Huisun Experimental Forest Station (HEFS) $\left(24^{\circ} 04^{\prime} \mathrm{N}\right.$; $\left.121^{\circ} 01^{\prime} \mathrm{E}\right)$ is situated in central Taiwan in Ren'ai Township, Nantou County (Fig. 1). HEFS is one of four forestry stations operated by the Department of Forestry, National

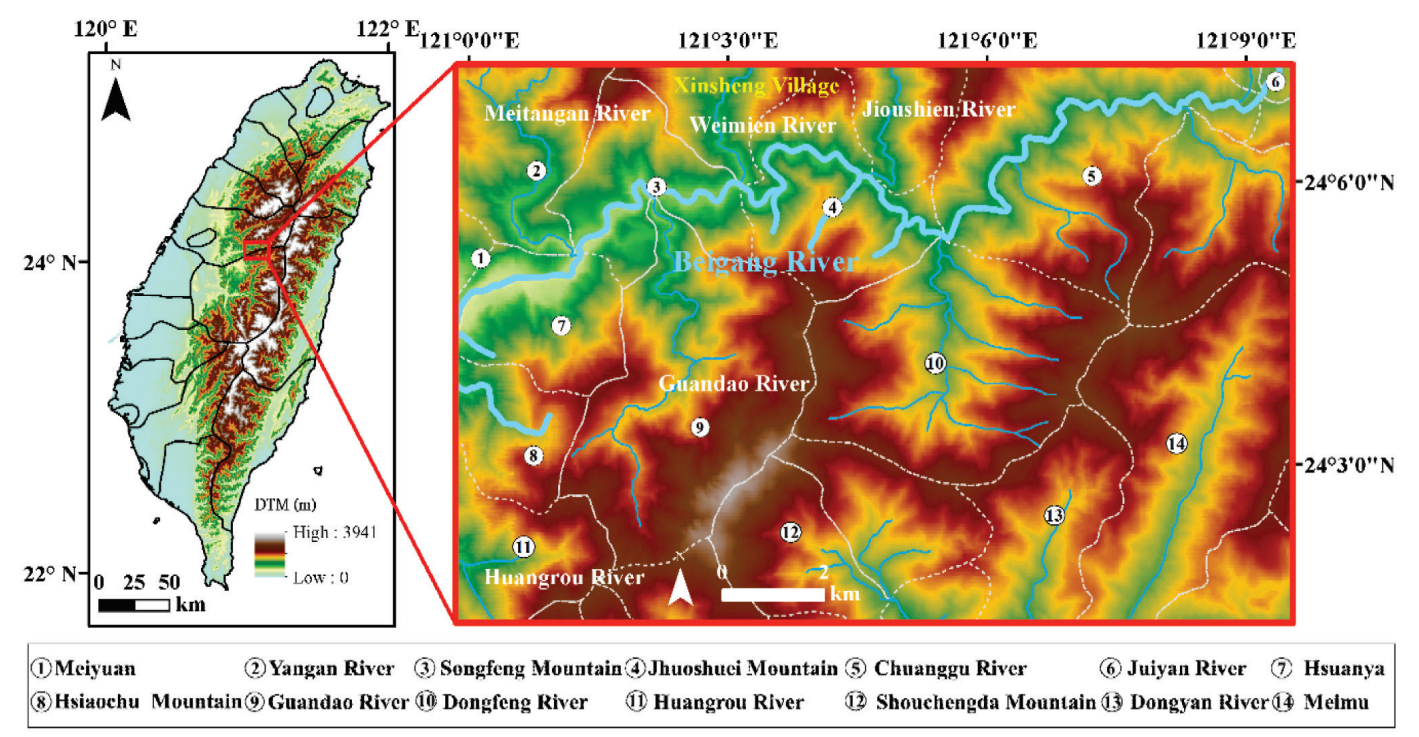

Fig. 1. Study site of Huisun Experimental Forest Station (HEFS). 
Chung Hsing University and comprises $77.47 \mathrm{~km}^{2}$ with the highest altitude of $2417 \mathrm{~m}$ located in the southern east part of Shouchen Mountain. Around $80 \%$ of HEFS area maintain the primitive forest, which is a valuable resource for both research and recreation purpose.

HEFS with a range in altitude from $433-2417 \mathrm{~m}$, nearly $2000 \mathrm{~m}$ of elevation difference. Beigang River flowing along this area coupled with the tributaries of Guandao river under the vigorous down cutting effect and the crisscrossed of high mountain deep valley, forming of majestic canyon, waterfall, torrent and other scenery. HEFS mostly are old-growth forest, comprising varieties of Taiwan-specific plants, native fish species and variety of rare animals, etc., can be used for teaching, academic research, ecology conservation and forestry new technology demonstration business premises.

This study investigates changes after the Chi-Chi earthquake in HEFS from 1999 till 2016. By using multi-date satellite images, the long-term change trajectory of HEFS can be evaluated by combining the analysis of vegetation index and landslide analysis. The flowchart of this study is illustrated in Fig. 2 and the information of used multi-date satellite images was provided in Table 1.

\subsection{Radiometric Correction for Multi-Date Satellite Image}

Radiometric correction for multi-date satellite image processing is essential and critical in conducting long-term spatial monitoring. Due to the different environmental conditions of image shooting at different times, spectral differences and atmospheric conditions need to be considered.
This study utilized histogram matching, a relative radiometric correction process, to adjust the radiometric properties based on 2012/10/17 image for all other images. Histogram matching is an algorithm that can make the grayscale histogram of one image become as similar as possible to the user-specified one. Additionally, histogram matching supports the best contrast enhancement to the ideal span of the brightness value of the output image and automatically avoids output image from becoming too bright or too dark by removing the extreme part of a normal distribution histogram (Jensen 2005).

\subsection{Normalized Difference Vegetation Index (NDVI) and Mean-Variance Analysis (MVA)}

Currently, this research is based on France SPOT satellite image data, collecting images before and after landslide happened, calculating NDVI based on the spectrum differences of vegetation. Additionally, a linear regression analysis is applied to evaluate the long-term trends of NDVI. Moreover, the Mean-Variance analysis (MVA) of NDVI is carried out in order to investigate vegetation index.

\subsubsection{NDVI}

NDVI calculation theorem is based on the green plant which will strongly absorb red light and reflect infrared, as a result the value of NDVI can reflect plant in the red spectrum portion and infrared spectrum portion difference (Rouse et al. 1974; Huete et al. 2002; Warner and Campagna 2009), and then used to evaluate the healthiness of the

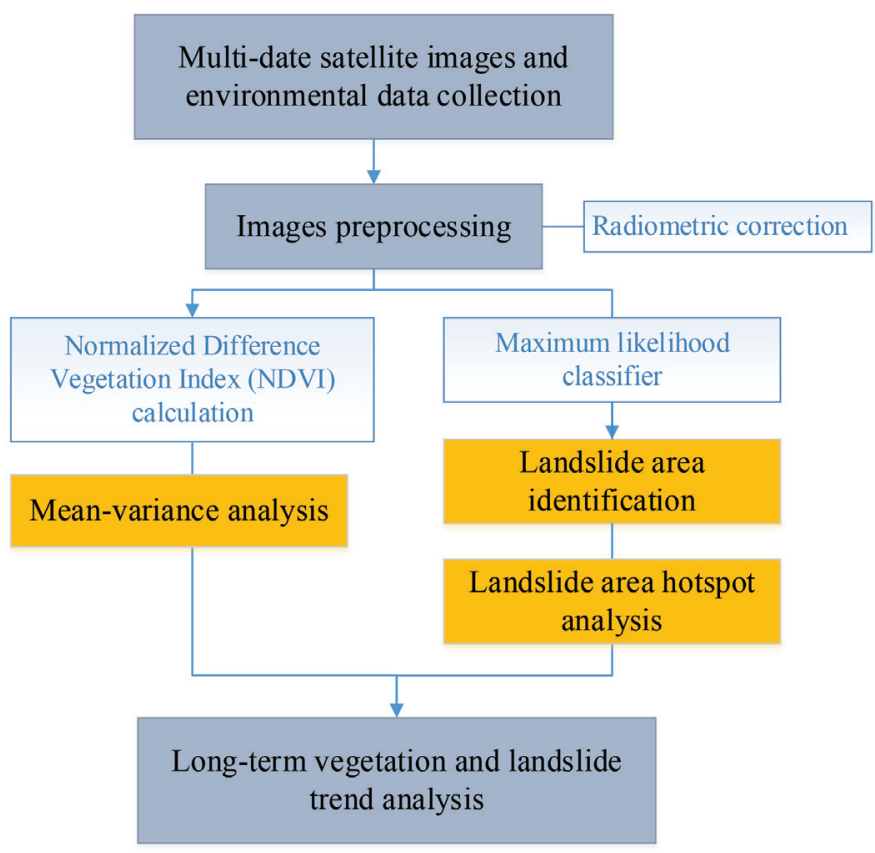

Fig. 2. Flowchart of the present study. 
Table 1. Satellite image date and corresponding information.

\begin{tabular}{|c|c|c|c|c|}
\hline Date & SPOT & Spatial resolution $(\mathbf{m})$ & Typhoon (TY) and heavy rain event & Description \\
\hline 1999/01/05 & SP1 & \multirow{6}{*}{20} & & \multirow{2}{*}{ Chi-Chi earthquake (1999/9/21) } \\
\hline $1999 / 10 / 31$ & SP4 & & & \\
\hline $2000 / 10 / 29$ & SP4 & & Bilis $(2000 / 8 / 21)$ & \\
\hline $2001 / 01 / 20$ & SP4 & & Xangsane (2000/10/30) & \\
\hline 2001/10/12 & SP4 & & $\begin{array}{l}\text { Toraji }(2001 / 7 / 28) \\
\text { Nari }(2001 / 9 / 13) \\
\end{array}$ & $\begin{array}{c}\text { Two bridges were submerged by mudslide, and parts of forest } \\
\text { land were destroyed }\end{array}$ \\
\hline 2002/01/08 & SP4 & & & \\
\hline 2003/07/07 & SP5 & \multirow{19}{*}{10} & Soudelor $(2003 / 6 / 16)$ & \\
\hline $2004 / 03 / 13$ & SP5 & & & \\
\hline $2004 / 07 / 10$ & SP5 & & Mindulle $(2004 / 6 / 28)$ & $\begin{array}{l}\text { Two bridges were submerged by mudslide causing traffic } \\
\text { congestion. }\end{array}$ \\
\hline $2005 / 11 / 11$ & SP5 & & $\begin{array}{l}\text { Haitang }(2005 / 07 / 16) \\
\text { Talim }(2005 / 08 / 30) \\
\text { Longwang }(2005 / 09 / 30)\end{array}$ & \\
\hline 2006/12/06 & SP5 & & & \\
\hline $2007 / 11 / 25$ & SP5 & & $\begin{array}{l}\text { Sepat }(2007 / 08 / 16) \\
\text { Krosa }(2007 / 10 / 04)\end{array}$ & \\
\hline $2008 / 05 / 14$ & SP5 & & & \\
\hline $2008 / 11 / 28$ & SP5 & & $\begin{array}{c}\text { Kalmaegi }(2008 / 07 / 16) \\
\text { Fung/wong }(2008 / 07 / 26) \\
\text { Sinlaku }(2008 / 09 / 11) \\
\text { Jangmi }(2008 / 09 / 26) \\
\end{array}$ & Meitangan River landslide (associated with TY Sinlaku) \\
\hline 2009/05/08 & SP5 & & & \\
\hline 2009/12/12 & SP5 & & Morakot (2009/08/05) & \\
\hline $2010 / 02 / 28$ & SP5 & & & \\
\hline $2010 / 12 / 21$ & SP5 & & & \\
\hline $2011 / 02 / 27$ & SP5 & & & \\
\hline $2011 / 09 / 18$ & SP5 & & Nanmadol (2011/08/27) & \\
\hline 2012/01/10 & SP5 & & & \\
\hline 2012/10/17 & SP5 & & $\begin{array}{c}\text { Heavy rain event }(2012 / 6 / 10) \\
\text { Tembin }(2012 / 08 / 26) \\
\text { Saola }(2012 / 07 / 30) \\
\end{array}$ & \\
\hline $2013 / 02 / 24$ & SP5 & & & \\
\hline $2014 / 08 / 29$ & SP5 & & $\begin{array}{c}\text { Soulik }(2013 / 07 / 11) \\
\text { Usagi }(2013 / 09 / 19) \\
\text { Matmo }(2014 / 07 / 21) \\
\end{array}$ & \\
\hline 2015/02/01 & SP5 & & & \\
\hline $2016 / 07 / 20$ & SP6 & 6 & $\begin{array}{c}\text { Dujuan }(2015 / 09 / 27) \\
\text { Soudelor }(2015 / 08 / 06) \\
\text { Nepartak }(2016 / 07 / 06) \\
\end{array}$ & \\
\hline
\end{tabular}


plant. NDVI calculation is expressed in Eq. (1):

$\mathrm{NDVI}=\frac{\mathrm{NIR}-\mathrm{RED}}{\mathrm{NIR}+\mathrm{RED}}$

The value of NDVI is between -1 and +1 . The formula of NDVI calculation could cancel out mostly of the deviation of radiation. A larger NDVI value indicates the plant was taking in so much of the infrared spectrum and so the plant is healthier but if the value is small then it is the contrary.

\subsubsection{Mean-Variance Analysis (MVA)}

Mean-Variance analysis (MVA) developed by Pickup and Foran (1987) is used to reveal the spatial and temporal pattern of vegetation indices (VIs) derived from remotely sensed data. Many scholars modified the method to define meaningful seasonal and inter-annual responses of vegetation to climate and disturbances (Tsai and Yang 2016). The MVA portrays dynamic systems graphically as a timeevolving process by plotting the mean of the vegetation index (VI) response versus its variance on a portrait.

\subsection{Landslide Identification}

The present study used supervised classification of Gaussian Maximum Likelihood Classifier for landslide identification from all images. Gaussian Maximum Likelihood Classifier is one of the supervised classification that requires assigned training sample data. After the training sample data are selected, the spectral characteristics of training sample data were extracted as a template to classify the whole image. The spectral characteristics of the training sample data such as homogeneous aggregation and heterogeneous separation have a great impact on the result so training sample data must be carefully chosen. The basics steps of Gaussian Maximum Likelihood Classifier are shown below:

(1) Decide the types of surficial coverage.

(2) Choose pixels from each category as a training sample.

(3) Calculate the probability of unknown pixel from each category.

(4) Assign the highest probability of occurrence to categorize unknown pixel.

As a result, it is assumed that the number of categories by the image is $\omega_{i} i=1,2, \ldots, n$, where $n$ represents the number of classes. To determine the types of each pixel $x$ or its various types of the probability of occurrence, the formula can be expressed as Eq. (2).

$P\left(\omega_{i} \mid x\right) \quad i=1,2, \ldots, n$

The classification is analysed according Eq. (3). if $P\left(\omega_{i} \mid x\right)>P\left(\omega_{j} \mid x\right)$ for all $j \neq i$

If $P\left(\omega_{i} \mid x\right)$ the probability of occurrence is the highest, then the pixel belong to the category $\omega_{i}$.

Assume each surficial coverage is in normal distribution, having sufficient training information, we could use these training information to estimate the distribution of each surficial coverage. Although $P\left(\omega_{i} \mid x\right)$ could not be obtained, $P\left(\omega_{i} \mid x\right)$ can be found from the training information and is expressed as Eq. (4).

$P\left(\omega_{i} \mid x\right)=P\left(x \mid \omega_{i}\right) P\left(\omega_{i}\right) / P(x)$

Among them, $P\left(\omega_{i}\right)$ is the probability of occurrence of category $\omega_{i}$. The way Gaussian Maximum Likelihood Classifier classify unknown pixel is likely using estimation of variations and correlation of spectral reaction patterns in each category. For this purpose, assume that the category training area formed by the distribution of the intensive points of the training sample area is the Gaussian value, that is, normal distribution. Under this assumption, the distributions of the board spectrum reaction form of each category can be expressed by the mean vector and the covariance matrix, the spectral response patterns and mean vectors is correlated. After having these parameters, the statistical probability of each unknown pixel can be calculated (Lillesand et al. 2008).

\subsection{Frequency of Landslide Occurrence}

The number of landslides occurs during 1999 to 2016 were calculated for each pixel $(10 \times 10 \mathrm{~m})$. By summing the number of occurrences, a frequency of landslide occurrence map was produced for further analyses regarding the relationship between the frequency of landslide with elevation, slope, aspect, and distance to the river.

\subsection{Hotspot Analysis}

Hotspot Analysis has been widely used in vegetation science (Fortin et al. 1990), plant spatial genetic structure (Takahashi et al. 2008), land pollutions (Zhang et al. 2008; De la Torre et al. 2012), road collision analysis (Manepalli et al. 2011), coral reef environment evaluations (LeDrew et al. 2000), and many other fields. The spatial hotspot calculates the degree of spatial autocorrelation based on a certain eigenvalue between the spatial unit and its surrounding units and then analyses the spatial distribution of these spatial units. Spatial autocorrelation analysis can be divided into global spatial autocorrelation and local spatial autocorrelation. Global autocorrelation can be used to determine the clustering characteristics in space based on the autocorrelation coefficients. Moran's I, an index developed by 
Moran in 1950, is the most commonly used measurement index of Global autocorrelation (Moran 1950). Regional autocorrelation can be used to calculate the scope of the cluster, and the degree of spatial autocorrelation (Anselin 1995). Getis-Ord $\mathrm{G}_{\mathrm{i}}{ }^{*}$ statistic was developed to identify the clustering of a low and high index of regional autocorrelation (Getis and Ord 1992). This study uses regional autocorrelation Getis-Ord $\mathrm{G}_{\mathrm{i}}$ * for hotspot analysis:

Getis-Ord $\mathrm{G}_{\mathrm{i}}^{*}$ is defined as:

$G_{i}^{*}(d)=\frac{\sum_{j=1}^{n} w_{i j}(d) x_{j}}{\sum_{j=1}^{n} x_{j}} j$ may equal to $i$

where $w_{i j}$ is a matrix of spatial weight between feature $i$ and $j ; d$ is distance; $w_{i j}(d)=1$ when $j$ within $d$ of $i$, otherwise, $w_{i j}(d)=0 ; x_{i}$ and $x_{j}$ is the attribute value for feature $i$ and $j ; n$ is the total number of features.

\section{RESULTS AND DISCUSSION}

\subsection{Images Pre-Processing}

This study utilized 26 SPOT images from 1999 to 2016 collected before and after natural disasters (Table 1) to investigate the landslide conditions and vegetation variation. All satellite images were pre-processed with geometric and radiation corrections, where radiation correction was based on histogram matching correction to minimize the influences from factors such as atmospheric condition, photographic condition, and landform factors, and so on.

\subsection{Mean-Variance Analysis of Normalized Difference Vegetation Index (NDVI)}

The mean and standard deviation values were calculated from the NDVI values derived from 26 SPOT satellite images of HEFS from 1999 to 2016 (Fig. 3). The results showed that the average NDVI was the highest before the Chi-Chi earthquake (0.523), and the average value decreased after the earthquake and fell to a minimum (0.485) in 2001. The NDVI standard deviation is the lowest $(0.08)$ before the earthquake and the highest (0.197) in 2003. At the same time, according to the results of linear regression analysis, the NDVI average has a slight upward trend and the NDVI standard deviation has a slight downward trend. It can be inferred that the overall vegetation status of HEFS has been gradually revived after the earthquake.

In this study, Mean-Variance analysis (Fig. 4) was used to investigate the spatial and temporal patterns of the overall vegetation status of HEFS. Figure 4 uses the mean value of NDVI and spatial variance value as the horizontal axis and the vertical axis respectively. An overall average of the NDVI mean and spatial variability is noted. The first quadrant in Fig. 4 has a high mean value and high spatial variability; the second quadrant has a high mean value and low spatial variability that indicates vegetation is in a stable state; the third quadrant has a low mean value and high spatial variability that means less vegetation exists and the landscape can be easily disturbed. The fourth quadrant is characterized by low mean and low spatial variability that illustrates a homogenous and degraded landscape with a small amount of vegetation. The results showed that the NDVI of HEFS was located in the second quadrant before the Chi-Chi earthquake representing a stable stage of vegetation status. After the earthquake occurred, values of mean and variance of NDVI shifted from the second quadrant to the fourth quadrant, which indicated the overall state of declining vegetation. During the period from 2000 to 2009, vegetation status has fluctuated across all quadrants. After the year of 2010, values of mean and variance of NDVI were mainly in the second quadrant that suggested the overall vegetation status had been stable with high NDVI values and low spatial variability.

\subsection{Landslide Area Identification}

Landslide area identification was conducted using Maximum-likelihood supervised classification and supplemented by artificially assisted interpretation. At the time of 1999/01/05 (before the Chi-Chi earthquake), only a large landslide was spotted in Xinsheng Village which was located in the Jhuoshuei Mountain catchment. The rest of landslides were scattered distributed across HEFS and small in size in several catchments in Beigang River basin (Juiyan River, Chuanggu River, Songfeng Mountain, Yangan Ricer, Hsuanya and Meiyuan catchments) and Dongyan River catchment in Wuxi River basin.

After the Chi-Chi earthquake, landslides areas expanded to a broader spatial coverage. Other than the abovementioned catchments, many small landslides were found in Huangrou River, Shouchengda Mountain, Guandao River, Hsiaochu Mountain, Meimu, and Dongfeng River catchments. In the year of 2008, a big landslide of $0.9 \mathrm{~km}^{2} \mathrm{oc}-$ curred near Meitangan River was triggered by Typhoon Sinlaku in September 2008 (Hsieh et al. 2016). This big landslide near Meitangan River was easy spotted in the satellite images taken since 2008/11/28, so-called Meitangan River landslide. Analysis of landslide characteristics including area, NDVI, aspect, slope, and height were carried out and discussed hereafter.

Figure 5 shows the time series of NDVI and total landslide areas from 1999 to 2016. The total landslide areas before the Chi-Chi earthquake is approximately $2 \mathrm{~km}^{2}$. After the earthquake, the average value of NDVI decreased and the area of landslides increased 1.5 times compared with the previous period $\left(3.1 \mathrm{~km}^{2}\right)$. Before 2008 , the amplitude of NDVI values and the landslide areas were large and fluctuated. After 2008, the averaged NDVI increased and the area 
of the landslide was relatively stable, approximately $5 \mathrm{~km}^{2}$.

The slope variations of landslides were categorized into three time periods, namely before the Chi-Chi earthquake (1999/01/05), after the earthquake to 2008, and 2009 - 2016 (Fig. 6). At the time before the Chi-Chi earthquake, landslides in HEFS were evenly distributed at 0 - 50 degrees and the size of landslides were relatively small. During the decade following the earthquake, landslides in HEFS were concentrated at 30 - 40 degrees (the 4 th grade slope based on the soil and water conservation technical specifications) with much larger sizes. The change of landslide sizes is considered to be highly related to the effects of the Chi-Chi earthquake on the disturbance of surface strata. At the time from 2009 - 2016, the concentration slope range shift to 20 - 30 degrees with smaller landslide sizes which indicates a lack of large-scale landslides and an overall stable status of HEFS.

The landslide elevation variations in HEFS in Fig. 7 show most landslide within the elevation of $500-1000$ and

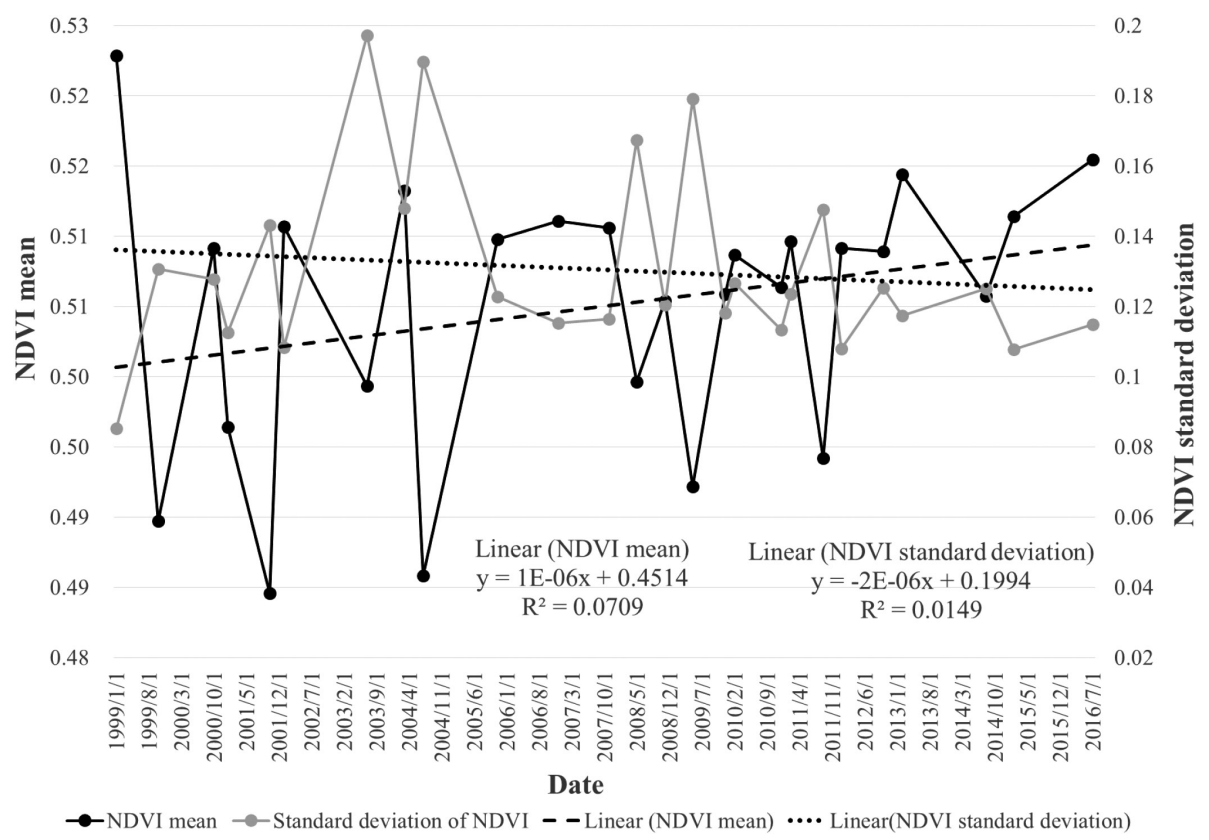

Fig. 3. NDVI time series of Huisun Experimental Forest Station.

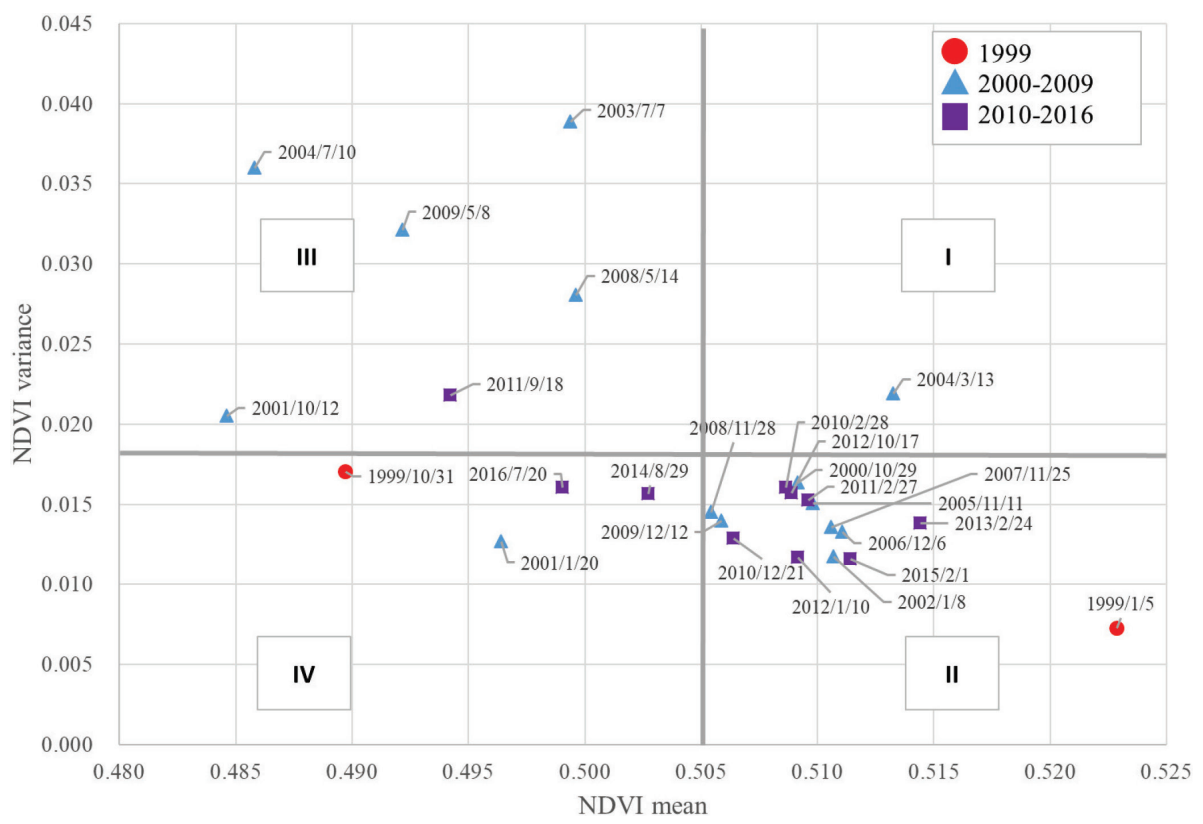

Fig. 4. NDVI Mean-Variance analysis of Huisun Experimental Forest Station. 


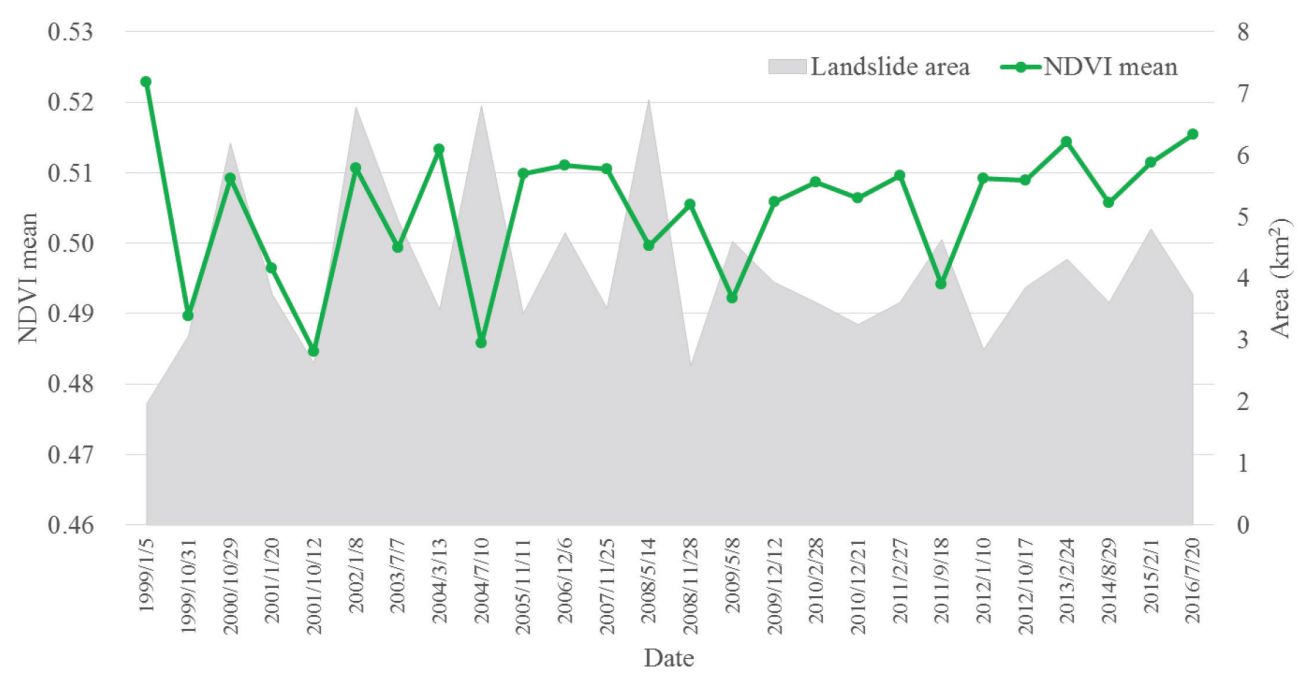

Fig. 5. Time series of NDVI mean and landslide area in Huisun Experimental Forest Station.
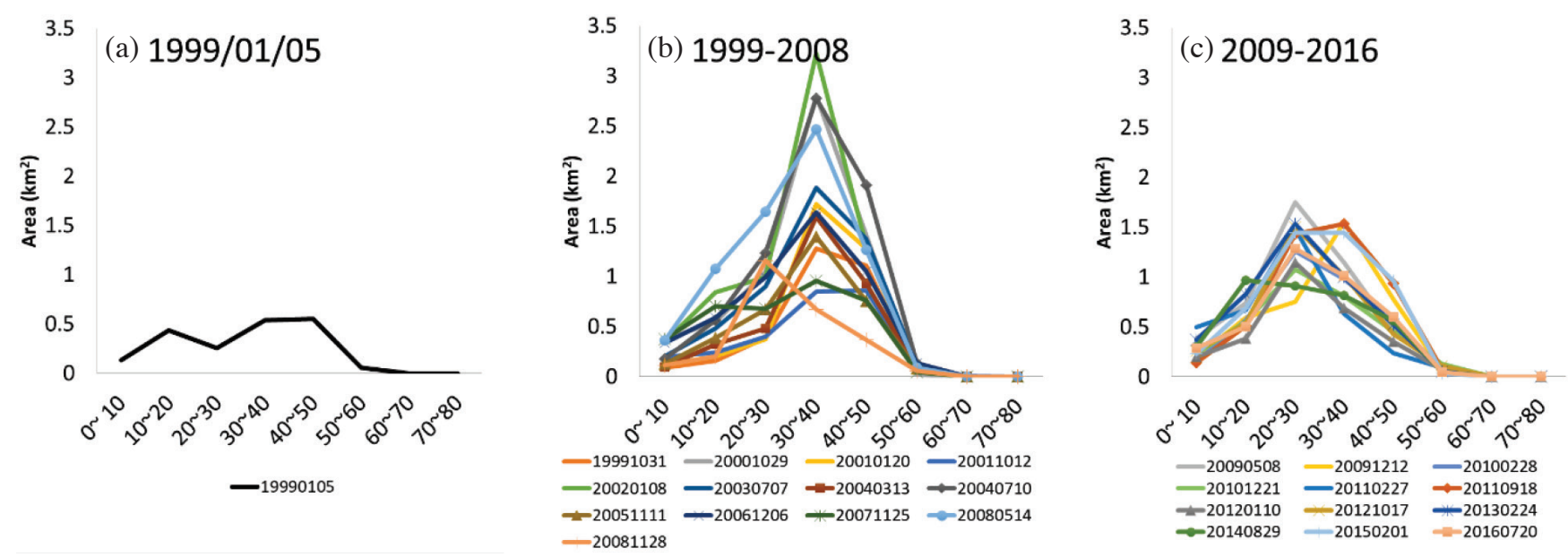

Fig. 6. Landslide area slope variations of Huisun Experimental Forest Station: (a) 1999/01/05, (b) 1999 - 2008 , and (c) 2009 - 2016.

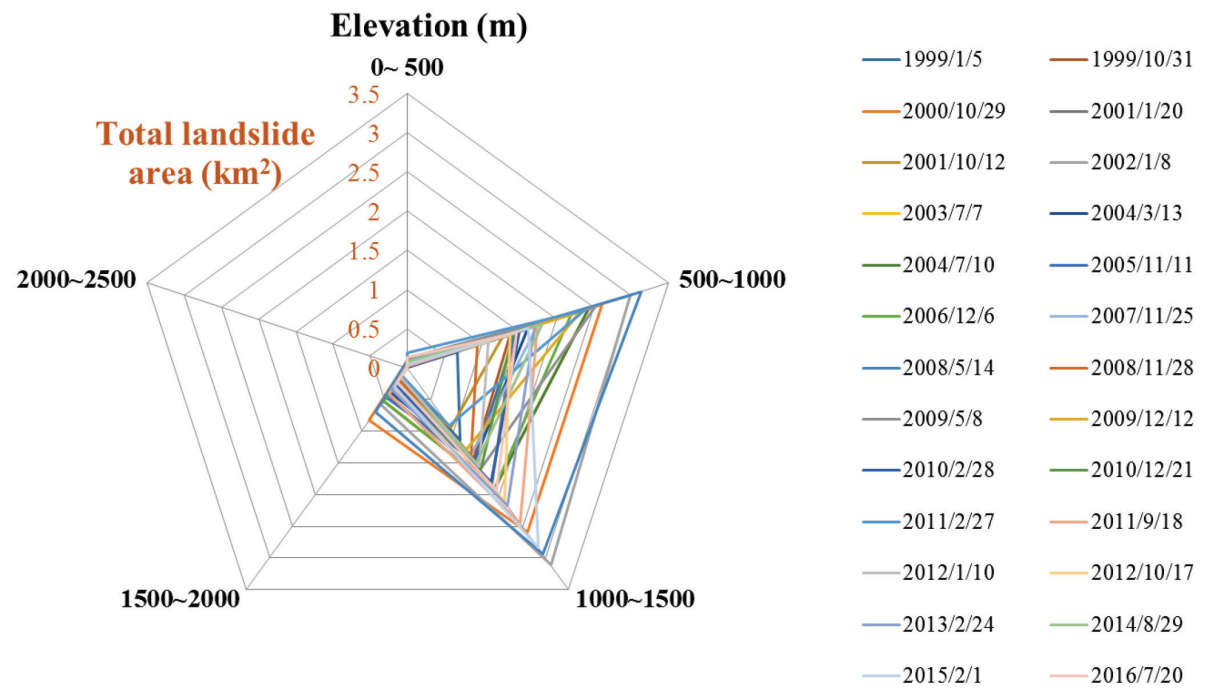

Fig. 7. Landslide area elevation variations of Huisun Experimental Forest Station. 
1000 - 1500 m. A small proportion of landslides occur in the elevation range of $1500-2000 \mathrm{~m}$ that is consistent with the research results of Feng and Lin (2003). The present study unifies the slope direction data of the landslide lands (Fig. 8), in which 28.75 and $28.71 \%$ of the landslides are SE-facing and S-facing slopes, respectively. In Taiwan, typhoon route is divided into 10 categories, in which only the 2nd category, passing over northern Taiwan heading to west or north-west, and the 3rd category, passing over central Taiwan heading to west or north-west, affect HEFS areas. According to the wind direction records from the two nearest weather stations, Renai and Meifeng stations, the most frequent wind direction during typhoon events in this area is SE. Bearing in mind that solar energy concentrates on S-facing slope and windward side of typhoons, the occurrence of landslides becomes more likely on SE-facing and S-facing slopes (Lu et al. 2011). Additionally, the aspect of the Meitangan River landslide is mainly SE-facing slope. Considering the relatively large size of the Meitangan River landslide, it is reasonable to expect the dominant aspects of landslides are the SE-facing slope.

\subsection{Frequency of Landslide Occurrence}

Figure 9 shows the results of the cumulative numbers of landslide occurrence based on identified landslides from 1999 to 2016 at a 10 square meters' pixel resolution. Higher values indicate a more frequent landslide occurrence and vice versa. In the Xinsheng Village area, the observed high value indicates a persistent landslide condition inferring poor vegetation coverage and bare land. Other observed high-value pixels mainly distributed along the Beigang River. Three categories of the observed number of landslide occurrences, 0 - 9, 10 - 16, and 17 - 26 times, were inves- tigated in terms of their characteristics of the slope, aspect, and distance to a river (Fig. 10).

According to the soil and water conservation technical specifications, slopes degrees are classified into six grades which are $0-5,5-15,15-30,30-40,40-55$, and $>55$ degrees, respectively. As shown in Table 2, among the three categories of landslide frequencies, the total area is proportional to the slope grade gradient, and the landslide area is the largest and the ratio exceeds $55 \%$ (6th grade of slope). The total landslide area was the largest in the 0 - 9 times category of $192.71 \mathrm{~km}^{2}$ while the total area of the landslide was 2.28 and $0.75 \mathrm{~km}^{2}$ in the $10-16$ and $17-26$ times categories, respectively.

In the 0 - 9 times category, landslides were found in almost every aspect (Table 3 ). In the 10 -16 and 17 - 26 times categories, higher percentages of landslides were found in SE-facing and S-facing slopes. In the 10 - 16 times category, 31.6 and $30.1 \%$ of landslides occurred on the SE-facing and S-facing slope, respectively. In the 17 - 26 times category, 35.8 and $45 \%$ of landslides occurred on the SE-facing and $\mathrm{S}$-facing slope, respectively. Due to two large landslide areas in the Xinsheng Village and Meitangan River are SE-facing and $\mathrm{S}$-facing, it is reasonable to expect the dominant aspects of landslides in HEFS are SE-facing and S-facing slopes.

Regarding the distance between the landslide and the river channel, this study uses a 50-m spacing buffer distances to exam the relationship between the distance to the river channel and three categories of landslide frequencies (Table 4). The results showed that more than $60 \%$ of the landslides in each category were located more than $200 \mathrm{~m}$ away from the river channel. However, for the rest of landslides, an inverse relationship was found between the landslide areas and the distance to a river channel in the $0-9$ and $10-16$ times categories. In the $17-26$ times category, a

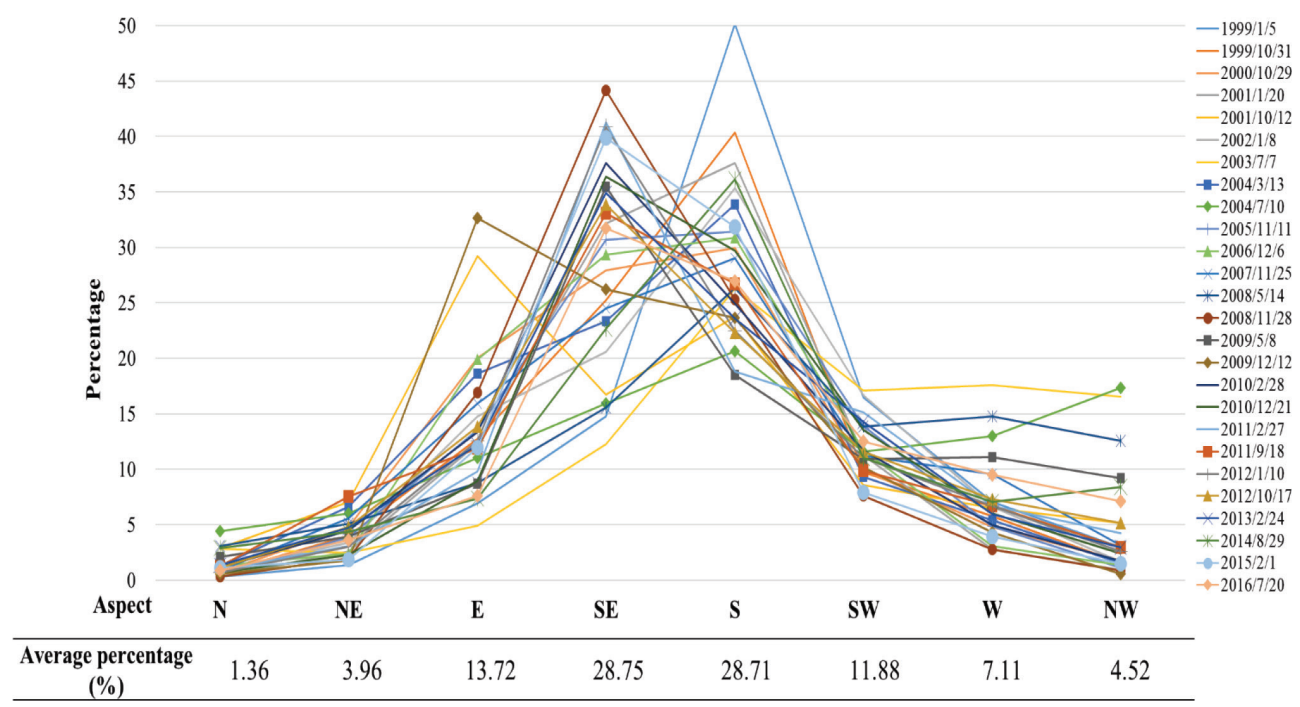

Fig. 8. Landslide area aspect percentage of Huisun Experimental Forest Station. 


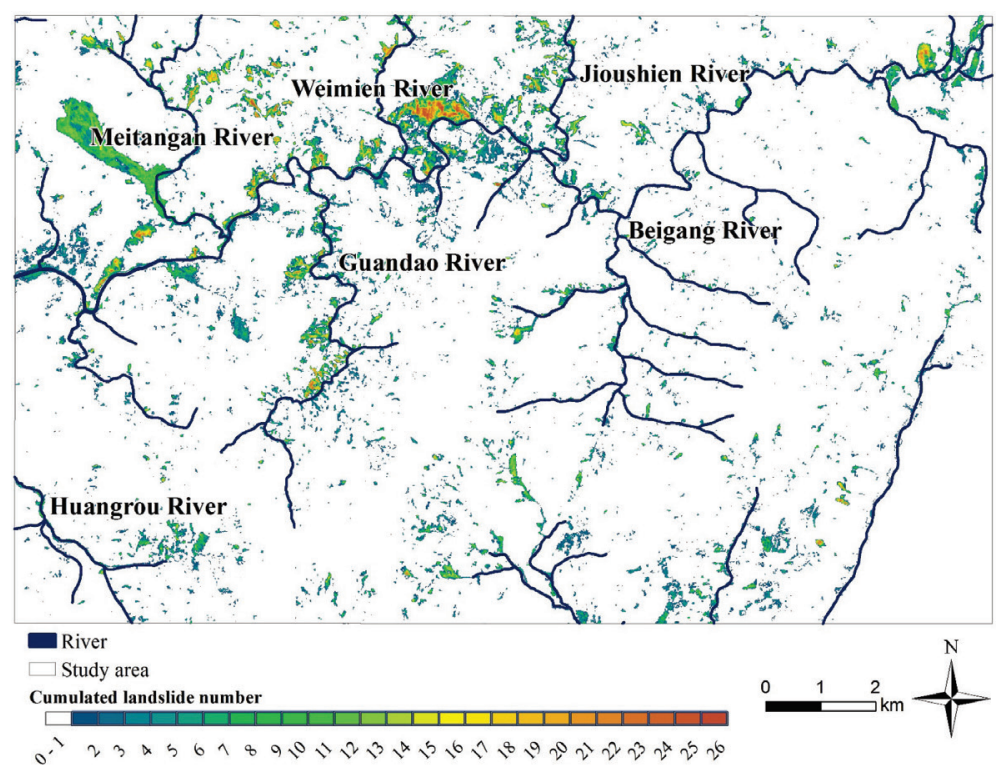

Fig. 9. Frequency of landslide occurrence in Huisun Experimental Forest Station.

(a)

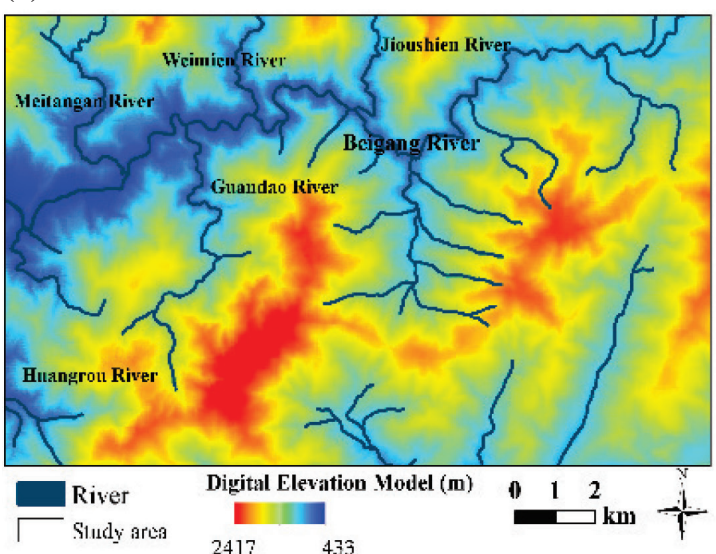

(c)

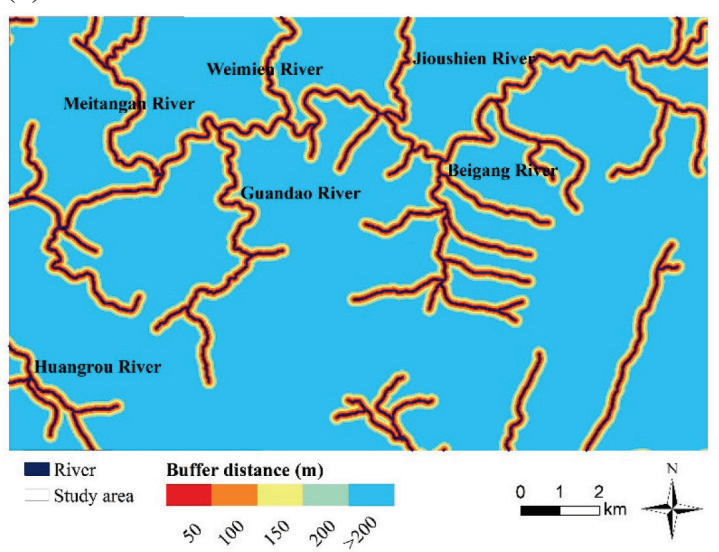

(b)

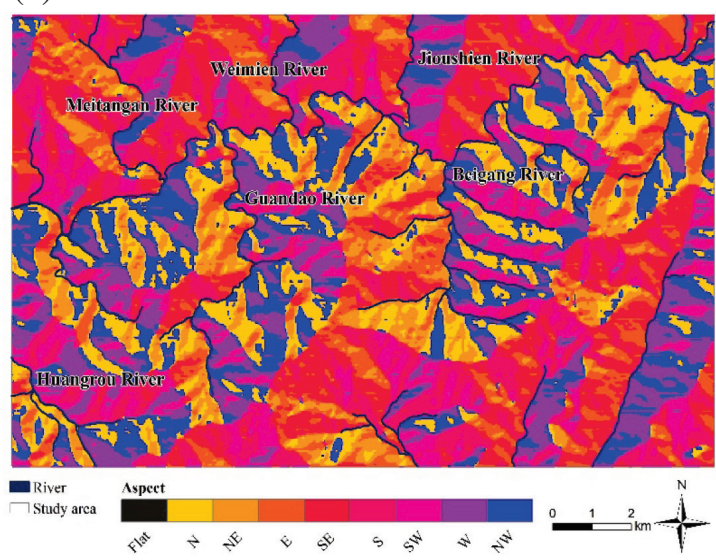

(d)

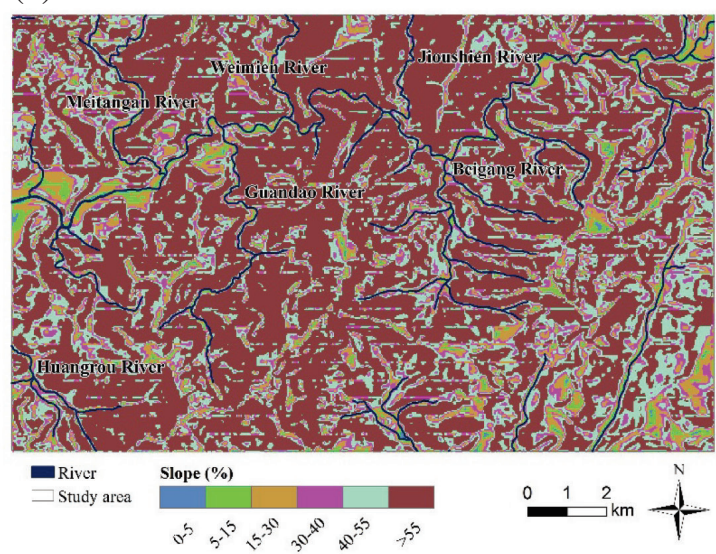

Fig. 10. Huisun Experimental Forest Station information: (a) DEM, (b) aspect, (c) river buffer, and (d) slope. 
Table 2. Slope variations of landslide frequency categories.

\begin{tabular}{c|ccc}
\hline Frequency & $\mathbf{0 ~ - ~ 9}$ & $\mathbf{1 0}-\mathbf{1 6}$ & $\mathbf{1 7 - 2 6}$ \\
\hline Slope (degree) & & $\mathrm{km}^{2}(\%)$ \\
\hline $\mathbf{0}-\mathbf{5}$ & $0.79(0.4)$ & $0.01(0.6)$ & $0.00(0.0)$ \\
$\mathbf{5}-\mathbf{1 5}$ & $5.57(2.9)$ & $0.09(4.0)$ & $0.00(0.0)$ \\
$\mathbf{1 5}-\mathbf{3 0}$ & $18.08(9.4)$ & $0.17(7.3)$ & $0.01(1.2)$ \\
$\mathbf{3 0}-\mathbf{4 0}$ & $18.83(9.8)$ & $0.24(10.4)$ & $0.02(2.9)$ \\
$\mathbf{4 0}-\mathbf{5 5}$ & $39.36(20.4)$ & $0.40(17.7)$ & $0.08(10.9)$ \\
$>\mathbf{5 5}$ & $\mathbf{1 1 0 . 0 8 ( 5 7 . 1 )}$ & $\mathbf{1 . 3 7}(\mathbf{6 0 . 0})$ & $\mathbf{0 . 6 4}(\mathbf{8 5 . 0})$ \\
Total area & 192.71 & 2.28 & 0.75 \\
\hline
\end{tabular}

Table 3. Aspect variations of landslide frequency categories.

\begin{tabular}{c|ccc}
\hline Frequency & $\mathbf{0 ~ - ~ 9 ~}$ & $\mathbf{1 0 - 1 6}$ & $\mathbf{1 7 - 2 6}$ \\
\hline Aspect & & $\mathrm{km}^{2}(\%)$ \\
\hline FLAT & $0.00(0.0)$ & $0.00(0.0)$ & $0.00(0.0)$ \\
$\mathbf{N}$ & $22.44(11.6)$ & $0.02(1.1)$ & $0.00(0.1)$ \\
NE & $17.93(9.3)$ & $0.12(5.0)$ & $0.01(1.6)$ \\
$\mathbf{E}$ & $22.52(11.7)$ & $0.38(16.6)$ & $0.08(10.7)$ \\
SE & $26.97(14.0)$ & $\mathbf{0 . 7 2 ( 3 1 . 6 )}$ & $0.27(35.8)$ \\
$\mathbf{S}$ & $24.79(12.9)$ & $0.69(30.1)$ & $\mathbf{0 . 3 4}(\mathbf{4 5 . 0})$ \\
SW & $23.03(12.0)$ & $0.21(9.0)$ & $0.04(5.4)$ \\
$\mathbf{W}$ & $27.37(14.2)$ & $0.11(5.0)$ & $0.01(1.4)$ \\
$\mathbf{N W}$ & $\mathbf{2 7 . 6 6 ( 1 4 . 4 )}$ & $0.03(1.5)$ & $0.00(0.0)$ \\
\hline
\end{tabular}

Table 4. River buffer variations of landslide frequency categories.

\begin{tabular}{c|ccc}
\hline Frequency & $\mathbf{0 ~ - ~ 9 ~}$ & $\mathbf{1 0 - 1 6}$ & $\mathbf{1 7 - 2 6}$ \\
\hline River buffer $(\mathbf{m})$ & \multicolumn{3}{|c}{$\mathrm{km}^{2}(\%)$} \\
\hline $\mathbf{0}-\mathbf{5 0}$ & $12.78(6.6)$ & $0.28(12.7)$ & $0.05(6.4)$ \\
$\mathbf{5 0}-\mathbf{1 0 0}$ & $11.79(6.1)$ & $0.23(10.4)$ & $0.09(12.0)$ \\
$\mathbf{1 0 0}-\mathbf{1 5 0}$ & $11.36(5.9)$ & $0.19(8.6)$ & $0.08(10.9)$ \\
$\mathbf{1 5 0}-\mathbf{2 0 0}$ & $10.97(5.7)$ & $0.16(7.0)$ & $0.08(10.1)$ \\
$>\mathbf{2 0 0}$ & $\mathbf{1 4 5 . 7 5 ( 7 5 . 7 )}$ & $\mathbf{1 . 3 6 ( 6 1 . 3 )}$ & $\mathbf{0 . 4 6}(\mathbf{6 0 . 5})$ \\
\hline
\end{tabular}

higher percentage of slides were found at 50 - 100 m's river buffer. The inverse relationship indicates a possible impact of drainage on the adjacent slopes that is in good agreement with a study conducted by Feng and Lin (2003).

\subsection{Hot Spot Analysis}

In this study, hot spot analysis was performed to identify patterns of spatial significance based on the cumulative number of landslide occurrence (Fig. 11). In addition, hot spots and cold spots with different significance levels were identified (Fig. 12). In general, the total area of cold spots is larger than the total area of hot spots. The hot spots area with $99 \%$ confidence interval is $5.5 \mathrm{~km}^{2}$, which is the largest area in the hot spots analysis. In addition to the two landslide areas of Xinsheng Village and Meitangan River, the distribution of the hot spots area with $99 \%$ confidence interval mainly occurred on the right bank of the middle section of Beigang River, Jioushien River, Weimien River, and Guantao River. The areas of cold spots with 95 and $99 \%$ confidence intervals are approximately equal size, which are 5.2 and $5 \mathrm{~km}^{2}$, respectively. Larger areas of cold spots are mostly distributed near the landslide of Xinsheng Village and the downstream of Beigang River.

Overall, the landslides identified in HEFS shows a stable trajectory in terms of its sizes and NDVI. Combining the results of mean variance analysis, landslide area, and NDVI time series (Figs. 4 and 5), landslides in HEFS move toward a relatively stable stage. Additionally, the hot spots are also coincident with SE-facing slope and locate relatively closer to the nearest river channel. A prior study conducted by Feng and Lin (2003) stated the landslide sizes in HEFS positively correlated with the distance to road and to river and even the closer the bigger. However, Feng and Lin (2003) also concluded aspect being not an important factor to landslides that is disapproved by the analysis in the present study. Compared with their study time period of 1987 to 2001 being mostly before the Chi-Chi earthquake and only two aerial photos being used, the present study covers a longer time span from 1999 to 2016 and 26 satellite images are used to provide a more comprehensive evaluation of landslide after the Chi-Chi earthquake in HEFS.

Moreover, topography is another important factor of landslides. According to a study conducted by Weissel and Stark (2001), seismically-triggered slope failures are found to be concentrated at and near ridge crest, however, heavy rains-caused slope failure mainly occur in saturated, colluvial hollows further down slope. In the present study, the relationship between topography and landslide can be illustrated by the largest landslide-Meiyuan Shan landslide, which is associated with Typhoon Sinlaku on 14 - 15 September 2008, occurred within Meitangan River basin in Beigang River system.

Furthermore, a prior study (Lin et al. 2006) investigated 


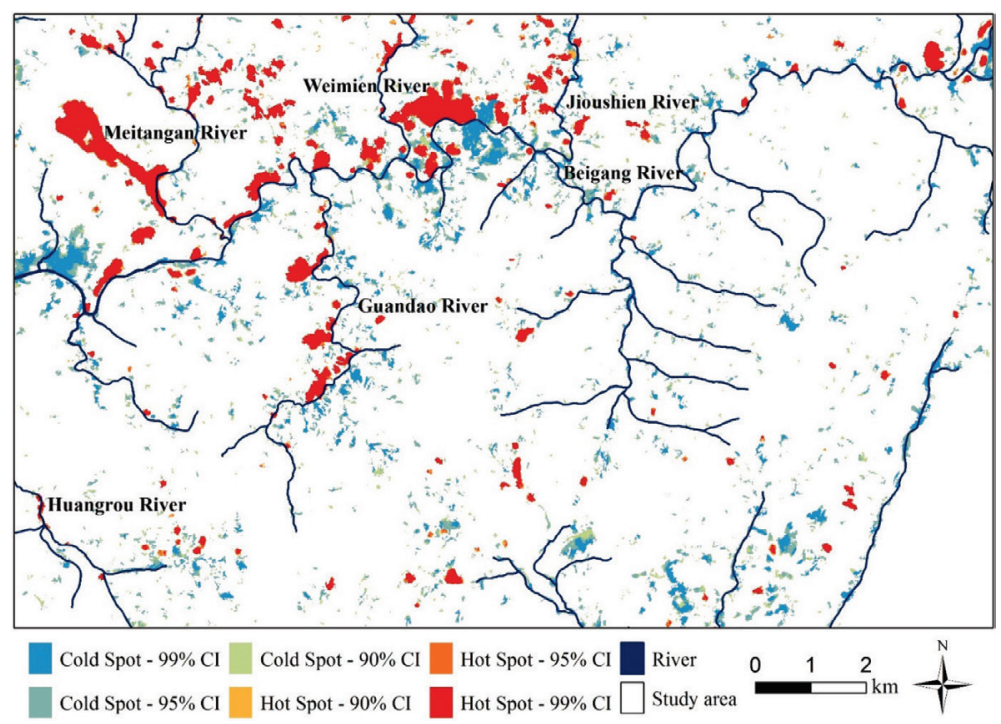

Fig. 11. Landslide hotspot analysis of Huisun Experimental Forest Station.

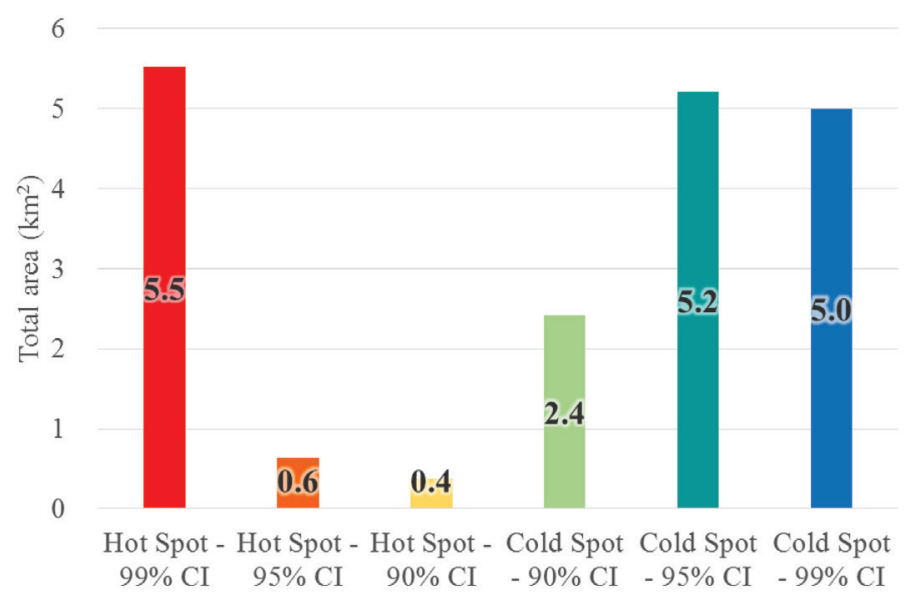

Fig. 12. Area of landslide hotspot analysis.

the impact of the Chi-Chi earthquake on subsequent rainfall-induced landslides in central Taiwan, and found that the rainfall-induced landslides occurred mainly in places with slopes between 40 and 50 degrees by using eight satellite images covering the study period from 1996 to 2001. The present study analyses 26 satellite images covering approximately two decades mostly after the Chi-Chi earthquake to provide updated and extensive analyses. The present study divides the pattern of slope variations into three time periods and discovers a noticeable change during a decade following the Chi-Chi earthquake and those years after 2008. During the decade following the earthquake, landslide often occurred on 30 - 40 degrees and had sizes larger than before the earthquake. Afterwards, in the time period of $2009-2016$ the concentration slope range shifts to $20-30$ degrees with smaller landslide sizes which indicates a lack of large-scale landslides and an overall stable status of HEFS.

\section{CONCLUSION}

Multi-date and multi-sensor satellite images coupled with a landslide identification process were used in this study to investigate the landslide pattern in spatial and temporal perspectives. The results reveal that total landslide areas decreased and NDVI value increased from 1999 to 2016 by analyzing 26 SPOT images. In addition, several characteristics of landslides, such as topography (slope, elevation, and aspect) and distance to the river, were also discerned.

Overall, the long-term landslide trends of HEFS is approaching a stable stage in terms of the slightly increasing mean NDVI value with decreasing NDVI variance. Based on the linear regression and Mean-Variance analyses, the total landslide areas were temporally fluctuated after the Chi-Chi earthquake and remained quite stable from 2008 to 2016. The slope characteristic of landslides changed to a 
concentration in 30 - 40 degree after the Chi-Chi earthquake. After 2008, the slope characteristic of landslides changed again to a concentration in 20 - 30 degree. Additionally, the size of the landslide is larger during a decade after the earthquake than the later years, 2008 to 2016. Spatially, two landslide areas of Xinsheng Village and Meitangan River were identified as hot spots with $99 \%$ confidence interval. In HEFS, more than $50 \%$ of landslides were observed in places of S-facing and SE-facing slopes, and the majority of landslides occurred at $500-1500 \mathrm{~m}$ elevation. Based on the frequency of landslide occurrence, the total landslide area is the largest in the $0-9$ times category. In the $10-16$ and 17 - 26 times categories, high percentages of landslides were found in SE-facing and S-facing slopes. An inverse relationship was found between the landslide areas and the distance to the river channel in the $0-9$ and $10-16$ times categories. The hot spot analysis identified areas with frequent landslide occurrence that provides a simple priority list for effective mitigation. Additionally, the hot spot analysis results are useful for the development of location-specific and helpful for intervention measure and assessing landscape dynamics.

Findings from the present study provide valuable knowledge of landslide patterns in HEFS and thus can serve as the reference for spatial planning and predicting unstable areas prone to landslides. In addition, this study can serve as a fundamental basis for understanding and even enhance modeling geo-processes related to landslide dynamics. Moreover, this study evaluates the present risk which is crucial to establishing early-warning systems and developing possible prediction models. Future climate change is likely to occur at an unpredictable speed and magnitude, which may lead to more extreme landslide triggering events. Therefore, a strong and sound historical spatio-temporal landslide analysis is urgently needed as the foundation of management and the greatest support for decision-making, especially in the context of global change. The significance of forming a reliable semi-auto or automated landslide identification and monitoring method becomes evident. Furthermore, establishing proper short-term and long-term landslides managing strategies, such as an early-warning system, is currently a feasible and beneficial approach to reduce risks and vulnerability under geomorphology and climatic influence for HEFS and places beyond.

Acknowledgements This research is partially supported by the Ministry of Science and Technology under Grant Number 106-2625-M-005-008, 107-2634-F-005-003 through "Pervasive AI Research (PAIR) Labs, Taiwan", 104-2923-E-492-002-MY3 through the "Center of Excellence for Cyber Enablement of Applications", and "Innovation and Development Center of Sustainable Agriculture" from The Featured Areas Research Center Program within the framework of the Higher Education Sprout Project by the Ministry of Education (MOE) in Taiwan.

\section{REFERENCES}

Adesuyi, A. S. and Z. Múnch, 2015: Using time-series NDVI to model land cover change: A case study in the Berg River catchment area, Western Cape, South Africa. Int. J. Environ. Chem. Eco. Geol. Geophys. Eng., 9, 553-558, doi: 10.5281/zenodo.1105775. [Link]

Alexakis, D. D., D. G. Hadjimitsis, and A. Agapiou, 2013: Integrated use of remote sensing, GIS and precipitation data for the assessment of soil erosion rate in the catchment area of "Yialias" in Cyprus. Atmos. Res., 131, 108-124, doi: 10.1016/j.atmosres.2013.02.013. [Link]

Anselin, L., 1995: Local indicators of spatial associationLISA. Geogr. Anal., 27, 93-115, doi: 10.1111/j.15384632.1995.tb00338.x. [Link]

Barrett, E. C., 2013: Introduction to Environmental Remote Sensing, Routledge, $480 \mathrm{pp}$.

Bhandari, A. K., V. K. Singh, A. Kumar, and G. K. Singh, 2014: Cuckoo search algorithm and wind driven optimization based study of satellite image segmentation for multilevel thresholding using Kapur's entropy. Expert Syst. Appl., 41, 3538-3560, doi: 10.1016/j. eswa.2013.10.059. [Link]

Bozzano, F., P. Mazzanti, D. Perissin, A. Rocca, P. De Pari, and M. Discenza, 2017: Basin scale assessment of landslides geomorphological setting by advanced InSAR analysis. Remote Sens., 9, 267, doi: 10.3390/ rs9030267. [Link]

Brandt, M., P. Hiernaux, K. Rasmussen, C. Mbow, L. Kergoat, T. Tagesson, Y. Z. Ibrahim, A. Wélé, C. J. Tucker, and R. Fensholt, 2016: Assessing woody vegetation trends in Sahelian drylands using MODIS based seasonal metrics. Remote Sens. Environ., 183, 215-225, doi: 10.1016/j.rse.2016.05.027. [Link]

Chang, J. and O. Slaymaker, 2002: Frequency and spatial distribution of landslides in a mountainous drainage basin: Western Foothills, Taiwan. Catena, 46, 285307, doi: 10.1016/S0341-8162(01)00157-6. [Link]

Chang, Y., M. A. Lee, K. T. Lee, and K. T. Shao, 2013: Adaptation of fisheries and mariculture management to extreme oceanic environmental changes and climate variability in Taiwan. Mar. Pol., 38, 476-482, doi: 10.1016/j.marpol.2012.08.002. [Link]

Chaussard, E., S. Wdowinski, E. Cabral-Cano, and F. Amelung, 2014: Land subsidence in central Mexico detected by ALOS InSAR time-series. Remote Sens. Environ., 140, 94-106, doi: 10.1016/j.rse.2013.08.038. [Link]

Czerepowicz, L., B. S. Case, and C. Doscher, 2012: Using satellite image data to estimate aboveground shelterbelt carbon stocks across an agricultural landscape. Agr. Ecosyst. Environ., 156, 142-150, doi: 10.1016/j. agee.2012.05.014. [Link]

De la Torre, A., I. Iglesias, M. Carballo, P. Ramírez, and M. 
J. Muñoz, 2012: An approach for mapping the vulnerability of European Union soils to antibiotic contamination. Sci. Total Environ., 414, 672-679, doi: 10.1016/j. scitotenv.2011.10.032. [Link]

Du, Y., Q. Xu, L. Zhang, G. Feng, Z. Li, R.-F. Chen, and C.-W. Lin, 2017: Recent landslide movement in Tsaoling, Taiwan tracked by TerraSAR-X/TanDEM-X DEM time series. Remote Sens., 9, 353, doi: 10.3390/ rs9040353. [Link]

Dutta, D., A. Kundu, N. R. Patel, S. K. Saha, and A. R. Siddiqui, 2015: Assessment of agricultural drought in Rajasthan (India) using remote sensing derived Vegetation Condition Index (VCI) and Standardized Precipitation Index (SPI). The Egyptian Journal of Remote Sensing and Space Science, 18, 53-63, doi: 10.1016/j. ejrs.2015.03.006. [Link]

Feng, F. L. and H. P. Lin, 2003: Analysis and restoration of landslide in HuiSun Forest Experimental Station after 921 Chi-Chi earthquake. Quart. J. For. Res. Of Taiwan, 23, 13-24.

Fortin, M.-J., P. Drapeau, and P. Legendre, 1990: Spatial autocorrelation and sampling design in plant ecology. In: Grabherr, G., L. Mucina, M. B. Dale, and C. J. F. Ter Braak (Eds.), Progress in Theoretical Vegetation Science, Advances in Vegetation Science, Vol. 11, Springer, Dordrecht, 209-222, doi: 10.1007/978-94009-1934-1_18. [Link]

Getis, A. and J. K. Ord, 1992: The analysis of spatial association by use of distance statistics. Geogr. Anal., 24, 189206, doi: 10.1111/j.1538-4632.1992.tb00261 .x. [Link]

Gopinath, G., 2015: Free data and Open Source Concept for Near Real Time Monitoring of Vegetation Health of Northern Kerala, India. Aquat. Procedia, 4, 14611468, doi: 10.1016/j.aqpro.2015.02.189. [Link]

Guan, Y., B. He, X. Li, C. Yin, and S. Qiu, 2017: Desertification assessment and trend analysis using MODIS data. 2017 IEEE International Geoscience and Remote Sensing Symposium (IGARSS), Fort Worth, TX, 5739-5742, doi: 10.1109/IGARSS.2017.8128311. [Link]

Hetland, E. A., P. Musé, M. Simons, Y. N. Lin, P. S. Agram, and C. J. DiCaprio, 2012: Multiscale InSAR time series (MInTS) analysis of surface deformation. J. Geophys. Res., 117, doi: 10.1029/2011JB008731. [Link]

Hsieh, Y. C., Y. C. Chan, and J. C. Hu, 2016: Digital elevation model differencing and error estimation from multiple sources: A case study from the Meiyuan Shan landslide in Taiwan. Remote Sens., 8, 199, doi: 10.3390/rs8030199. [Link]

Huete, A., K. Didan, T. Miura, E. P. Rodriguez, X. Gao, and L. G. Ferreira, 2002: Overview of the radiometric and biophysical performance of the MODIS vegetation indices. Remote Sens. Environ., 83, 195-213, doi: 10.1016/S0034-4257(02)00096-2. [Link]
Jensen, J. R., 2005: Introductory Digital Image Processing: A Remote Sensing Perspective, Third Edition, Pearson Prentice Hall Press, 526 pp.

Johnson, K. M. and W. B. Ouimet, 2014: Rediscovering the lost archaeological landscape of southern New England using airborne light detection and ranging (LiDAR). J. Archaeol. Sci., 43, 9-20, doi: 10.1016/j. jas.2013.12.004. [Link]

LeDrew, E. F., M. Wulder, and H. Holden, 2000: Change detection of satellite imagery for reconnaissance of stressed tropical corals. IGARSS 2000 Proceedings, IEEE 2000 International Geoscience and Remote Sensing Symposium, Taking the Pulse of the Planet: The Role of Remote Sensing in Managing the Environment (Cat. No.00CH37120), Vol. 6, 2678-2680, doi: 10.1109/IGARSS.2000.859679. [Link]

Lee, C. T., 2017: Landslide trends under extreme climate events. Terr. Atmos. Ocean. Sci., 28, 33-42, doi: 10.3319/TAO.2016.05.28.01(CCA). [Link]

Li, S., S. Yang, X. Liu, Y. Liu, and M. Shi, 2015: NDVIbased analysis on the influence of climate change and human activities on vegetation restoration in the Shaanxi-Gansu-Ningxia region, Central China. Remote Sens., 7, 11163-11182, doi: 10.3390/rs70911163. [Link]

Lillesand, T., R. W. Kiefer, and J. Chipman, 2008: Remote Sensing and Image Interpretation, Sixth Edition, John Wiley \& Sons, $756 \mathrm{pp}$.

Lin, C.-H., 2015: Abundant landslides associated with extreme weather change during the 2009 Typhoon Morakot. Terr. Atmos. Ocean. Sci., 26, 351-353, doi: 10.3319/TAO.2015.03.06.01(T). [Link]

Lin, C.-W., W.-S. Chang, S.-H. Liu, T.-T. Tsai, S.-P. Lee, Y.-C. Tsang, C.-L. Shieh, and C.-M. Tseng, 2011a: Landslides triggered by the 7 August 2009 Typhoon Morakot in southern Taiwan. Eng. Geol., 123, 3-12, doi: 10.1016/j.enggeo.2011.06.007. [Link]

Lin, C. Y., H. M. Lo, W. C. Chou, and W. T. Lin, 2004: Vegetation recovery assessment at the Jou-Jou Mountain landslide area caused by the 921 Earthquake in Central Taiwan. Ecol. Model., 176, 75-81, doi: 10.1016/j.ecolmodel.2003.12.037. [Link]

Lin, J. Y., M. D. Yang, B. R. Lin, and P. S. Lin, 2011b: Risk assessment of debris flows in Songhe Stream, Taiwan. Eng. Geol., 123, 100-112, doi: 10.1016/j.enggeo.2011.07.003. [Link]

Lin, W. T., C. Y. Lin, and W. C. Chou, 2006: Assessment of vegetation recovery and soil erosion at landslides caused by a catastrophic earthquake: A case study in Central Taiwan. Ecol. Eng., 28, 79-89, doi: 10.1016/j. ecoleng.2006.04.005. [Link]

Lu, S.-Y., C.-Y. Lin, and L.-S. Hwang, 2011: Spatial Relationships between Landslides and Topographical Factors at the Liukuei Experimental Forest, Southwestern 
Taiwan after Typhoon Morakot. Taiw. J. Forest Sci., 26, 399-408, doi: 10.7075/TJFS.201112.0088. [Link]

Lu, Z. and D. Dzurisin, 2014: InSAR imaging of Aleutian volcanoes. InSAR Imaging of Aleutian Volcanoes: Monitoring a Volcanic Arc from Space, Springer, Berlin, Heidelberg, 87-345, doi: 10.1007/978-3-64200348-6_6. [Link]

Maeda, E. E., Y. M. Moura, F. Wagner, T. Hilker, A. I. Lyapustin, Y. Wang, J. Chave, M. Mõttus, L. E. Aragão, and Y. Shimabukuro, 2016: Consistency of vegetation index seasonality across the Amazon rainforest. Int. J. Appl. Earth Observation Geoinformation, 52, 42-53, doi: 10.1016/j.jag.2016.05.005. [Link]

Mancini, F., M. Dubbini, M. Gattelli, F. Stecchi, S. Fabbri, and G. Gabbianelli, 2013: Using unmanned aerial vehicles (UAV) for high-resolution reconstruction of topography: The structure from motion approach on coastal environments. Remote Sens., 5, 6880-6898, doi: 10.3390/rs5126880. [Link]

Manepalli, U. R. R., G. H. Bham, and S. Kandada, 2011: Evaluation of hotspots identification using kernel density estimation (K) and Getis-Ord (Gi*) on I-630. Proceedings of the 3rd International Conference on Road Safety and Simulation, Indianapolis, USA. Available at http://onlinepubs.trb.org/onlinepubs/conferences/2011/RSS/2/Manepalli,UR.pdf.

Moran, P. A. P., 1950: Notes on continuous stochastic phenomena. Biometrika, 37, 17-23, doi: 10.2307/2332142. [Link]

Peña, J. M., J. Torres-Sánchez, A. I. de Castro, M. Kelly, and F. López-Granados, 2013: Weed mapping in early-season maize fields using object-based analysis of unmanned aerial vehicle (UAV) images. PloS One, 8, e77151, doi: 10.1371/journal.pone.0077151. [Link]

Pickup, G. and B. D. Foran, 1987: The use of spectral and spatial variability to monitor cover change on inert landscapes. Remote Sens. Environ., 23, 351-363, doi: 10.1016/0034-4257(87)90046-0. [Link]

Plowright, A. A., N. C. Coops, B. N. Eskelson, S. R. Sheppard, and N. W. Aven, 2016: Assessing urban tree condition using airborne light detection and ranging. $U r$ ban Forestry and Urban Greening, 19, 140-150, doi: 10.1016/j.ufug.2016.06.026. [Link]

Pope, G. and P. Treitz, 2013: Leaf area index (LAI) estimation in boreal mixedwood forest of Ontario, Canada using light detection and ranging (LiDAR) and WorldView-2 imagery. Remote Sens., 5, 5040-5063, doi: 10.3390/rs5105040. [Link]

Pravalie, R., I. Sîrodoev, and D. Peptenatu, 2014: Detecting climate change effects on forest ecosystems in Southwestern Romania using Landsat TM NDVI data. J. Geogr. Sci., 24, 815-832, doi: 10.1007/s11442-0141122-2. [Link]

Qi, S., Y. Zou, F. Wu, C. Yan, J. Fan, M. Zang, S. Zhang, and R. Wang, 2017: A Recognition and Geological Model of a Deep-Seated Ancient Landslide at a Reservoir under Construction. Remote Sens., 9, 383, doi: 10.3390/rs9040383. [Link]

Rouse, J. W., R. H. Haas, J. A. Schell, and D. W. Deering, 1974: Monitoring vegetation systems in the Great Plains with ERTS. In: Freden, S. C., E. P. Mercanti, and M. A. Becker (Eds.), Third Earth Resources Technology Satellite-1 Symposium, Volume I: Technical Presentations, NASA SP-351, NASA, Washington, D.C., 309.

Takahashi, T., N. Tani, K. Niiyama, S. Yoshida, H. Taira, and Y. Tsumura, 2008: Genetic succession and spatial genetic structure in a natural old growth Cryptomeria japonica forest revealed by nuclear and chloroplast microsatellite markers. For. Ecol. Manage., 255, 28202828, doi: 10.1016/j.foreco.2008.01.055. [Link]

Tsai, F., J. H. Hwang, L. C. Chen, and T. H. Lin, 2010: Postdisaster assessment of landslides in southern Taiwan after 2009 Typhoon Morakot using remote sensing and spatial analysis. Nat. Hazards Earth Syst. Sci., 10, 2179-2190, doi: 10.5194/nhess-10-2179-2010. [Link]

Tsai, H. P. and M. D. Yang, 2016: Relating vegetation dynamics to climate variables in Taiwan using 19822012 NDVI3g data. IEEE J. Selected Topics Appl. Earth Observations Rem. Sens., 9, 1624-1639, doi: 10.1109/JSTARS.2015.2511742. [Link]

Tsai, H. P., Y.H. Lin, and M. D. Yang, 2016: Exploring long term spatial vegetation trends in Taiwan from AVHRR NDVI3g dataset using RDA and HCA analyses. Remote Sens., 8, 290, doi: 10.3390/rs8040290. [Link]

Turner, D., A. Lucieer, and C. Watson, 2012: An automated technique for generating georectified mosaics from ultra-high resolution unmanned aerial vehicle (UAV) imagery, based on structure from motion (SfM) point clouds. Remote Sens., 4, 1392-1410, doi: 10.3390/ rs4051392. [Link]

Vibrans, A. C., R. E. McRoberts, P. Moser, and A. L. Nicoletti, 2013: Using satellite image-based maps and ground inventory data to estimate the area of the remaining Atlantic forest in the Brazilian state of Santa Catarina. Remote Sens. Environ., 130, 87-95, doi: 10.1016/j.rse.2012.10.023. [Link]

Wang, A. H., C. Y. Kung, I. C. Wu, and I. C. Yu, 2016: Collection and Analysis of the Cold Damage in Taiwan in January 2016. Newsletter of National Science and Technology Center for Disaster Reduction, 15. (in Chinese)

Warner, T. A. and D. J. Campagna, 2009: Remote Sensing with IDRISI Taiga: A Beginner's Guide, Geocarto International Centre, $297 \mathrm{pp}$.

Weissel, J. K. and C. P. Stark, 2001: Landslides triggered by the 1999 Mw7.6 Chi Chi earthquake in Taiwan and their relationship to topography. IGARSS 2001, Scanning the Present and Resolving the Future, 
Proceedings of the IEEE 2001 International Geoscience and Remote Sensing Symposium (Cat. No.01CH37217), Sydney, NSW, Australia, 759-761, doi: 10.1109/IGARSS.2001.976627. [Link]

Yang, M. D., 2007: A genetic algorithm (GA) based automated classifier for remote sensing imagery. Can. J. Rem. Sens., 33, 203-213, doi: 10.5589/m07-020. [Link]

Yang, M. D., Y. F. Yang, and S. C. Hsu, 2004: Application of remotely sensed data to the assessment of terrain factors affecting the Tsao-Ling landslide. Can.J. Rem. Sens., 30, 593-603, doi: 10.5589/m04-025. [Link]

Yang, M. D., T. C. Su, C. H. Hsu, K. C. Chang, and A. M. Wu, 2007: Mapping of the 26 December 2004 tsunami disaster by using FORMOSAT-2 images. Int. J. Remote Sens., 28, 3071-3091, doi: 10.1080/01431160601094500. [Link]

Yang, M. D., J. Y. Lin, C. Y. Yao, J. Y. Chen, T. C. Su, and C. D. Jan, 2011: Landslide-induced levee failure by high concentrated sediment flow - A case of ShanAn levee at Chenyulan River, Taiwan. Eng. Geol., 123,
91-99, doi: 10.1016/j.enggeo.2011.07.006. [Link]

Yang, M. D., S. C. Chen, and H. P. Tsai, 2017a: A LongTerm Vegetation Recovery Estimation for Mt. Jou-Jou Using Multi-Date SPOT 1, 2, and 4 Images. Remote Sens., 9, 893, doi: 10.3390/rs9090893. [Link]

Yang, M. D., K. S. Huang, Y. H. Kuo, H. Tsai, and L. M. Lin, 2017b: Spatial and Spectral Hybrid Image Classification for Rice Lodging Assessment through UAV Imagery. Remote Sens., 9, 583, doi: 10.3390/ rs9060583. [Link]

Yang, W., M. Wang, and P. Shi, 2013: Using MODIS NDVI time series to identify geographic patterns of landslides in vegetated regions. IEEE Geosci. Rem. Sens. Lett., 10, 707-710, doi: 10.1109/LGRS.2012.2219576. [Link]

Zhang,C., L.Luo, W. Xu, and V.Ledwith, 2008: Use of local Moran's I and GIS to identify pollution hotspots of $\mathrm{Pb}$ in urban soils of Galway, Ireland. Sci. Total Environ., 398, 212-221, doi: 10.1016/j.scitotenv.2008.03.011. [Link] 